Article

\title{
The Ecology of Autogamy in Wild Blueberry (Vaccinium angustifolium Aiton): Does the Early Clone get the Bee?
}

\author{
Francis A. Drummond $1, *\left(\mathbb{D}\right.$ and Lisa J. Rowland ${ }^{2}$ \\ 1 School of Biology and Ecology, University of maine, 5722 Deering, Orono, ME 04469, USA \\ 2 Genetic Improvement of Fruits and Vegetables Laboratory, Henry A. Wallace Beltsville Agricultural Research \\ Center, U.S. Department of Agriculture-Agricultural Research Service, Beltsville, MD 20705, USA; \\ Jeannine.Rowland@usda.gov \\ * Correspondence: fdrummond@maine.edu; Tel.: +1-207-944-4122
}

Received: 15 July 2020; Accepted: 5 August 2020; Published: 7 August 2020

\begin{abstract}
Wild blueberry, Vaccinium angustifolium Aiton, for the most part requires cross-pollination. However, there is a continuum across a gradient from zero to $100 \%$ in self-compatibility. We previously found by sampling many fields that $20-25 \%$ of clones during bloom have high levels of self-compatibility ( $\geq 50 \%$ ). In 2009-2011, and 2015 we studied the ecology of self-pollination in wild blueberry, specifically its phenology and bee recruitment and subsequent bee density on bloom. We found that highly self-compatible clones were predominantly early blooming genotypes in the wild blueberry population. On average, fruit set and berry weight were highest in self-compatible genotypes. The bumble bee community (queens only early in the spring) was characterized by bees that spent large amounts of time foraging in self-compatible plant patches that comprised only a small proportion of the blueberry field, the highest density in the beginning of bloom when most genotypes in bloom were self-compatible. As bloom proceeded in the spring, more plants were in bloom and thus more land area was occupied by blooming plants. The absolute density of bumble bee queens per $\mathrm{m}^{2}$ declined, as a dilution effect, and this probably resulted in lower fruit set throughout the field.
\end{abstract}

Keywords: ericacae; pollen transfer; allogamy; self-compatibility; fruit set; bee activity synchrony

\section{Introduction}

Wild blueberry is a North American fruit crop species that has not been genetically improved through breeding such as highbush blueberry, Vaccinium corymbosum L. [1]. This crop is a wild complex of ericaceous species that are part of eastern North American forests [2]. After harvesting the forest, these ericaceous plants are managed to provide access to sunlight, release from competition with weeds, reduction of insect pests and plant pathogens, and increased soil fertility [3]. Any given blueberry field can range in the number of wild blueberry species present. Vaccinium angustifolium Aiton, $V$. myrtilloides michx., V. angustifolium $\times V$. corymbosum hybrids, V. boreale I.V. Hall and Alders, and $V$. pallidum Aiton are the putative species and hybrids that represent wild blueberry $[2,4]$. The most abundant species are V. angustifolium, the sweet lowbush blueberry, and V. myrtilloides, the velvetleaf or sourtop lowbush blueberry [5]. Commercial fields are solely comprised of these two species across most of the geographic production region in maine, USA [2]. However, V. angustifolium is by far the dominant species managed for commercial production $[3,6]$. Wild blueberry is a valuable commercial berry crop in the northeastern U.S. (Maine and to a lesser extent New Hampshire, massachusetts, and Michigan), and eastern Canada (New Brunswick, Nova Scotia, Prince Edward Island, Newfoundland and Labrador, and Quebec). 
Wild blueberry yield depends upon adequate pollination [7,8]. genetically distinct individuals (referred to as clones) spread horizontally, developing shoots from underground rhizomes [3]. Wild blueberry pollination is almost entirely dependent upon bees $[7,9,10]$, although moths [11], flies and hummingbirds [FAD pers. obs.] have been reported visiting flowers. Because this crop is not planted, the spatial genetic pattern between individual plants in a field is not due to any pre-determined plan as in many crops such as almond, apples, peaches, highbush blueberry, or coffee [12-15]. This is important because wild blueberry is an insect dependent allogamous species $[9,16,17]$ and outcross compatibility is non-reciprocal [18]. This means that pollen movement between two clones may result in a high level of fruit set in one direction (clone 1 to clone 2), but a low level of fruit set in the other direction (clone 2 to clone 1). Because of this, the spatial genetic relationship among clones in a field and the number and species of bees that are present during bloom will determine the level of fruit set and subsequent crop yields [19,20].

There is still much that is not known about wild blueberry reproduction. Several investigations into the plant role in wild blueberry pollination and plant reproduction have advanced our knowledge into the areas of tradeoffs in reproductive effort investment [21,22], reproductive self-incompatibility/compatibility [17,18,23-25], spatial genetic structure and relatedness [26-28], reproductive tissue investment [29], gene flow measured as pollen movement from donor to recipient clone [30,31], timing of flower bud production [9,32] and flowering [9,32], plant plasticity in regards to physiological responses in growth and development and the effects of climate warming on blueberry pollination [33,34]. One topic that has not been researched is the ecology of autogamy in the reproduction of wild blueberry, the focus of this study.

Wild blueberry is a tetraploid $(2 \mathrm{n}=4 \mathrm{x}=48)$ and based upon morphological characters, it is hypothesized to be either an autotetraploid of $V$. boreale [35] or an allo-tetraploid of $V$. boreale $\times V$. pallidum or $V$. boreale $\times V$. myrtilloides [36,37]. An autotetraploid origin may be more likely as in general, tetraploid evolution in plants is thought to be most common through autotetraploidy processes compared to alloploidy [38]. Vaccinium angustifolium has been shown to have tetrasomic inheritance [25,28,39]. Wild blueberry is considered a self-sterile species requiring outcrossing $[17,18,24]$. However, mating self-compatibility (i.e., self-fertility) in wild blueberry plants has been measured in the field. It is believed to be a minor characteristic of wild blueberry populations. A range of self-compatibility has been found to exist in both maine and Canada ranging from 5-22\% of clones with levels of self-fertilization greater than $40 \%[18,23,24]$. However, self-compatibility in clones appears not to be a dichotomous property, but a continuous gradient ranging from $0-100 \%$ as measured by fruit set from self-pollination $[18,19]$. Some neighboring clones within populations have been found to be highly inter-related $[27,28,39]$ possibly in part due to self-pollination. This is thought to contribute to what has been estimated as high levels of inbreeding depression [25] and high genetic load [18].

While the presence of self-compatible clones in wild blueberry fields has been documented, the pollination ecology has not been well studied. Simulation modeling of non-reciprocal outcrossing (where fruit set resulting from pollen transferred from clone " $\mathrm{A}$ " to the stigma of clone " $\mathrm{B}$ " is not the same as the converse [18,19]) as well as pollination of self-compatible clones has been conducted [18]. Clone size has been shown to be a significant determinant of field-level fruit set in these simulations due to the self-pollination that takes place in clones with high levels of self-sterility. However, balancing this deleterious effect, the presence of self-compatible clones increases field-level fruit set and yield [19].

In general, the evolution of self-compatibility in plant populations is thought to occur and be maintained because it reduces extinction in numerically small founding populations, despite high levels of inbreeding depression [40-43]. However, studies with some plant species have not shown this to be the case [44]. It has been theorized that the evolutionary advantage of self-compatibility may be more likely in extinction threatened plant species such as species endemic to isolated islands [43]. Lloyd's theory of "reproductive assurance" states that plant species will evolve self-compatibility if there is at least some opportunity for outcrossing [44]. The environment and life history of wild blueberry suggests that one environment that might benefit self-compatible clones and yet still allow 
outcrossing is in the very beginning of bloom. Our hypothesis for this study was that bloom progression is gaussian in its distribution $[9,32]$ and so self-compatible clones that are the earliest blooming plants have exclusive access to all the pollinators in the field resulting in high fruit set. Later as bloom progresses and neighboring clones begin to bloom, these early blooming self-compatible clones that are still producing flowers and have viable long-lived flowers [9] have access to outcrossed pollen from bees that have visited the neighboring clones in bloom. Therefore, the objectives of this study were to: (1) describe the bloom phenology of self-compatible clones relative to clones more dependent upon outcrossing, (2) provide a measure of the dynamics between native bee density (using bumble bee queens as an example) and the progression of bloom in wild blueberry fields with reference to self-compatible clones, and (3) discuss both the evolutionary and grower perceived cost/benefit balance for self-compatible clones being "early bloomers".

\section{Materials and methods}

\subsection{Field Sites}

All research was conducted in maine, USA. Field studies for assessing fruit set in clones initiating flowering in the early, mid, and late part of the bloom season were conducted in the spring and summers of 2009, 2010, 2011, and 2015 either at a commercial grower's field in the town of Jonesport (Washington Co., $44^{\circ} 32^{\prime} 11.64^{\prime \prime} \mathrm{N}, 67^{\circ} 35^{\prime} 51.06^{\prime \prime} \mathrm{W}(2009)$ ); the University of maine Blueberry Hill Research Station, Jonesboro (Washington Co., $44^{\circ} 38^{\prime} 38.02^{\prime \prime}$ N, $67^{\circ} 38^{\prime} 47.39^{\prime \prime} \mathrm{W}(2010,2011)$ ); or in a commercial field in Winterport (Waldo Co., $44^{\circ} 40^{\prime} 28.19^{\prime \prime} \mathrm{N}, 68^{\circ} 57^{\prime} 34.89^{\prime \prime} \mathrm{W}$ (2015)). Field studies assessing bumble bee activity-densities were conducted in three commercial wild blueberry fields in

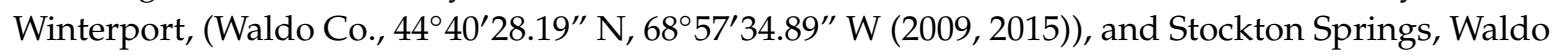
Co. $\left(44^{\circ} 32^{\prime} 25.11^{\prime \prime} N, 68^{\circ} 52^{\prime} 53.32^{\prime \prime} \mathrm{W}(2010)\right)$. Samples taken back to the laboratory to be processed, data entry, and statistical analysis, took place at the University of maine, Orono, Maine.

\subsection{Effects of Bloom Phenology Class and Pollination Type on Fruit set and Yield (Weight per Berry)}

In 2009, 2010, 2011, and 2015 clones initiating flowering early in bloom ( $\leq 100$ degree-days (DD), base $4{ }^{\circ} \mathrm{C}$ accumulated since 1 April, see the phenological bloom model developed and validated by Drummond [9]), mid-bloom (200-400 DD, only 2010, 2011, 2015), and late bloom ( $\geq 500$ DD) were arbitrarily selected and marked in the field with colored stakes. Each clone was given an identification code that was recorded on the stake. Stems (ramets) within clones (genets) were selected based upon similar morphology (stem color, leaf color, flower petal color and size, trichome density on leaves and stems). Previous research using genetic analysis of ramets suggest that morphology can be used fairly reliably to select stems within clones as belonging to a single clone $[18,31,45]$. In addition, to minimize error in stem selection we did not choose any clones that were adjacent and similar in morphology for this study. The number of clones selected each year were as follows. Twelve early clones and 4 late blooming clones (2009); 15 clones each of early, mid and late bloom phenology (2010); 10 clones each of early, mid, and late bloom phenology (2011); and 10 clones each of early, mid, and late bloom phenology (2015) were involved in the study. Hand pollination of flowers with "self" pollen (taken from flowers of the clone to be pollinated) was conducted to determine clones that are self-fertile and those that are not self-fertile and require outcrossing with other clones for successful fertilization, fruit set, and seed set. It has been shown that self-fertility in wild blueberry is a continuum from $0-100 \%$ [19]. However, only $20 \%$ of all clones are characterized as self-fertile at a level that results in at least $60 \%$ fruit set [18]. Sixty percent fruit set was the threshold level that we used in this study to define clones that are highly self-fertile. Although somewhat arbitrary, we felt it was instructive for assessing the differences between highly self-fertile clones and those that are more dependent upon outcrossing.

During the 4 years of this study, 20-30 stems in each selected clone were enclosed by fine mesh nylon bags that prevented access to the flowers by insects before flowers opened. When flowers began to open (dependent upon their bloom phenology), 5-10 stems per clone were each marked with labeled 
colored string and chosen as an open-pollination treatment. In addition, $3-5$ bagged stems with flowers that were $1-3 \mathrm{~d}$ old were cut. These stems were brought into the laboratory and were laid out upon laboratory benches for $24 \mathrm{~h}$ at room temperature $\left(18-22^{\circ} \mathrm{C}\right)$. Pollen was collected from the opened flowers on the cut stems into glass petri dishes by sonication using a vibrating tuning fork $(440 \mathrm{~Hz})$ placed against the corollas. Extracted pollen was applied to stems of the same clone that the pollen came from for self-pollinations. Pollen was placed on all floral stigmas in flowers (3-8) on the terminal flower clusters on each of 3-5 stems. Pollinations were carried out in the field immediately after the removal of the fine mesh nylon bags, using a small paint brush to apply pollen in sufficient, nonlimiting amounts (determined by a preliminary dosage study [45]). The number of flowers hand pollinated on each marked and labeled stem was recorded. These stems represented the self-pollination treatment. Bags were replaced on stems that had hand pollinated flowers and not removed again until petal fall and calyx swelling (initial sign of fruit set). In preliminary experiments in 2007, Bell [45] found that bags did not affect fruit set or the rate of fruit maturation when removed at the end of bloom (petal fall).

Ten to fourteen $\mathrm{d}$ after bloom (early-mid-June), clones in both pollination treatments and bloom phenology classes were visited, and marked stems in both the open-pollinated and self-pollination treatments were located. The period between the end of bloom and estimation of fruit set allowed for many of the inadequately or non-pollinated flowers to drop [46]. green fruit were counted on terminal flower clusters and proportion fruit set was estimated by dividing the number of fruits by the number of flowers recorded in the terminal cluster (see [7] for more detail). After fruits were mature, marked stems were cut and brought into the laboratory where individual fruits were weighed to the nearest one-thousandth of a gram. The 2010 data set was incomplete while all other years involved collecting data on both treatments (bloom phenology class, hand self-pollination and open pollination). The clones with early bloom phenology in 2010 experienced a frost resulting in the death of many flowers and so fruit set and berry weight were not used in any analyses. In addition, stems that experienced flower mortality due to disease were not included in the analyses. Data on open pollination was not collected in 2010.

\subsubsection{Bloom Phenology of Highly Self-Fertile Clones}

To determine if differences in the proportion of highly self-fertile clones occurred between the three bloom phenology classes, the proportion of clones with high self-fertility (using a threshold of $60 \%$ or greater fruit set) in the hand-crossed flowers for each clone was compared. Our hypothesis was that highly self-fertile clones would be more abundant compared to obligate outcrossing clones in the beginning of bloom when few clones are in bloom. Nominal logistic regression was used [47] to test this hypothesis. Bloom phenology class, year, and the interaction between year and bloom phenology class were the independent variables and the proportion of highly self-fertile clones was the nominal binomial independent variable. A Tukey HSD multiple comparison test was used to determine if the proportion of highly self-fertile clones differed among bloom phenology classes [47].

\subsubsection{Fruit Set and Berry Weight as Determined by Bloom Phenology Class and Pollination Type}

To assess overall patterns in plant productivity, two mixed models were constructed [47], one for fruit set and one for berry weight. Our hypothesis was that productivity as measured by fruit set and berry weight would be highest in the open pollinated treatment, and it would increase with the progression of bloom. The rationale behind our thinking was that most blueberry clones are obligate for outcrossing [17-19,23], and potential compatible pollen collected by bees from neighboring clones increases as bloom progresses. The fixed effects were bloom phenology class (early, mid, late), pollination type (hand vs. open), and their interaction. The random effect was year and its interaction with the fixed effects. The dependent variables were mean proportion fruit set and mean berry weight per clone. The validities of fit models were evaluated with the Chi-square Convergence Test [47]. Fixed teffects were tested using Satterthwaite's method for estimating denominator degrees 
of freedom [48]. Wald tests were used for random effects by evaluating slope estimates relative to 0.0 [47].

Because the mixed models for fruit set and berry weight are confounded by including both highly self-fertile clones along with self-incompatible clones, it is difficult to interpret the results, although it is what many researchers and growers would observe if they sampled these productivity metrics during bloom. In order to partially separate out the effects of highly self-fertile clones on fruit set and berry weight, mixed models were constructed for both the hand self-pollinated flowers and the open pollinated flowers where clones were identified as either highly self-fertile or not. Because we defined highly self-fertile clones as those that achieved at least $60 \%$ fruit set through hand self-pollination, the outcome of fruit set and self-fertility was determined by our threshold. However, we still show the results. The fixed effects for the mixed models were bloom phenology class, self-fertility level (high or not), and their interaction. Year was a random effect along with its interactions with the fixed effects and the dependent variables were fruit set and berry weight. models were assessed as described above. In addition, in order to interpret the effect of self-fertility on yield, the relationship between fruit set and berry weight was assessed using a mixed model with fruit set as a fixed effect and year and its interactions with the fixed effects as random effects. The dependent variable was berry weight. The conditional coefficient of determination was calculated for this relationship from the mixed model results [47].

\subsection{Bee Activity-Density Sampling}

The objective of this study was to determine if bee density is greater during the beginning of bloom compared to later in the season as bloom progresses. The hypothesis was that, early in bloom, bees numerically respond and aggregate to the limited floral resources offered in blueberry fields and that as fields continue blooming, the greater percentage of the field in bloom dilutes or reduces bee density on a per $\mathrm{m}^{2}$ basis as the community density of bees spreads out across the field. Bumble bees were selected as a measure of pollination intensity throughout bloom because they are the most efficient pollinator of wild blueberry [49], and their density (queens) is assumed to be relatively constant during bloom. They emerge from overwintering prior to bloom and do not produce workers until the end of bloom or after bloom finishes. In addition, bumble bee queens forage over long distances and unlike other wild bees they are found both along field edges and in field interiors [50]. Our hypothesis was that bumble bee density decreases during the bloom season, on a per unit area of bloom. We reasoned that this is due to the relatively constant number of bumble bee queens in the habitat during bloom, but an increasing floral resource as bloom progresses, an increasing floral resource dilution effect.

In the springs of 2009, 2010 and 2015, three commercial wild blueberry fields were sampled for wild bumble bee queens throughout bloom. The fields were 12-20 ha in area and no pesticides were applied during the spring. Starting in early may (4 may, 5 may, 4 may; 2009-2015, respectively) in all three years, fields were sampled for clones in bloom and bumble bee queens (Bombus spp.). In order to determine the proportion of field area comprised of wild blueberry clones in bloom, three $100 \mathrm{~m}$ straight line transects were walked in the field every two-ten days until just past full bloom on 10 June 2009, 25 may 2010 and 5 June 2015. Starting points of the transects in the field and direction were arbitrarily selected. For each transect on each sample date, when a clone was crossed by the transect, a note was made of whether the clone was in bloom, and then the diameter (if clone area resembled a circle) or diameters (if clone resembled an ellipse), or sides of the clone (if clone was a rectangle or polygon) were measured with a tape to the nearest $\mathrm{cm}$ so that areas of the clones could be calculated and the proportion of clones in the field in bloom could be estimated (for more detail of method see [51]). Bee activity-density measurements were initiated when bloom commenced and continued every 2-5 days through may. This was accomplished by placing ten, $1 \mathrm{~m}^{2}$ quadrats (made of $1.9 \mathrm{~cm}$ ID PVC pipe) in blooming clones (1-3/clone depending upon clone size). After deployment of the quadrats, each was sequentially approached slowly from a direction where no shadows were cast upon the quadrat. Once the observer was $1 \mathrm{~m}$ from a quadrat edge, $1 \mathrm{~min}$. was spent still before 
assessing bee activity-density. For $1 \mathrm{~min}$, the number of bees entering the quadrat was counted and the bee taxon group was recorded. After the $1 \mathrm{~min}$. measurement, another quadrat was observed until all 10 were completed, see [7] for more details on sampling bees. The average and standard error number of bees $/ \mathrm{m}^{2} /$ minute was calculated for each bee taxon on each sample date. A mixed repeated measures general linear model was used to determine the dilution effect of progressive bloom on bumble bee activity-density [47]. Percent bloom was the fixed effect and the random effects were: year, year $\times$ bloom, and sample date as the repeated measure. The dependent variable in the model was bumble bee queen activity-density (bees $/ \mathrm{m}^{2} / \mathrm{min}$.). model fit and appropriateness was evaluated following the procedures described above (Section 2.2.2). Non-linear marquardt least squares [47] was used to model the individual years' cumulative bloom progression and the dilution of queen bumble bees during the progression of bloom. An increasing sigmoidal asymptotic model was used to model cumulative bloom progression. This is an appropriate model as previously shown by Drummond [9]. A sigmoidal decay model was chosen for modeling bumble bee queen dilution because our hypothesis was that as bloom increased in a sigmoidal manner, bumble bee queen density would directly track the increasing field area in bloom and therefore would be characterized by an asymptotic decline over time. The form of the model for both cases is:

$$
\mathrm{Y}=\mathrm{a} /\left[1+\mathrm{e}^{(\mathrm{b}+\mathrm{c} \times \text { date })}\right]
$$

where:

$\mathrm{a}$ is the asymptote,

$\mathrm{b}$ is a shape parameter (positive for bloom, negative for bee dilution),

$\mathrm{c}$ is a slope parameter (negative for bloom, positive for bee dilution).

A repeated-measures mixed model was constructed to test if increasing bloom over time resulted in a decrease in bumble bee activity-density over the three years [47]. The fixed effect was proportion bloom, the random effect was days nested within year, and a compound symmetry covariance structure was assumed. The mixed model was evaluated as described above.

\section{Results}

\subsection{Bloom Phenology of Highly Self-Fertile Clones}

Logistic regression on the proportion of highly self-fertile clones provided evidence that year $(p=0.629)$ was not a significant predictor of the proportion of clones that are highly self-fertile. The year $\times$ phenology bloom class could not be estimated due to the unbalanced design (no early blooming clones in 2010). The proportion of highly fertile clones did differ according to bloom class phenology $\left(\chi^{2}(2)=8.137, p=0.017\right)$. A greater proportion of highly self-fertile clones occur in early bloom compared to mid and late bloom (Figure 1). 


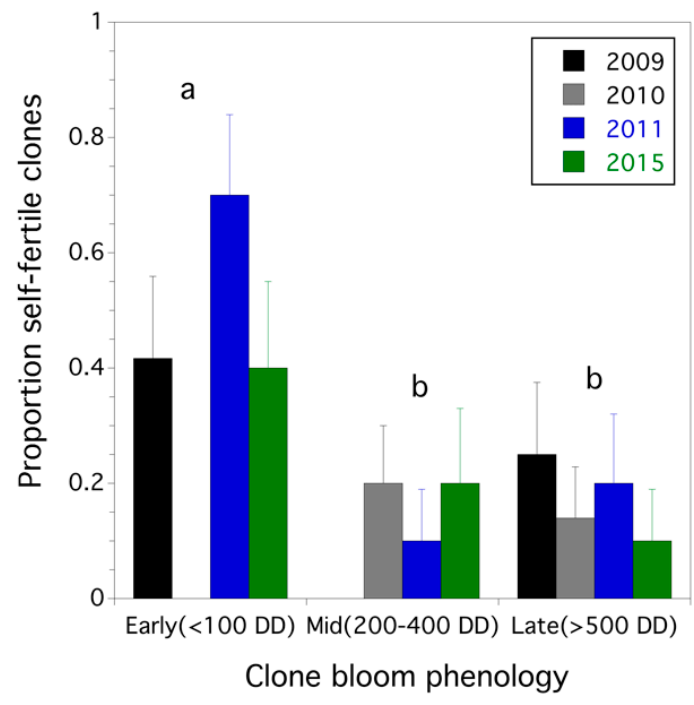

Figure 1. The proportion of highly self-fertile clones according to the period in bloom that they begin to flower (early, mid, and late bloom). Letters associated with bloom phenology classes that are the same are not significantly different (Tukey HSD, $\alpha=005$ ).

\subsection{Fruit Set and Blueberry mass of Highly Self-Fertile Clones}

The overall fruit set for clones that initiated flowering in the early, mid, and late bloom period can be described as an interaction between pollination type (hand self-pollination vs. open pollination) and bloom phenology class $\left(F_{(2,166.2)}=3.108, p=0.047\right)$. There was no random year effect or year interactions with fixed effects on fruit set $(p>0.05)$. The pattern of this interaction is shown in Figure 2 . Self-pollination in the early part of the bloom season resulted in significantly higher fruit set than in midseason blooming clones (Figure 2A). Open pollination resulted in no difference in fruit set throughout the bloom season among clones (early-late bloom) and no difference between the same clones that were self-pollinated (Figure 2B). Berry weight was only affected by bloom phenology class $\left(F_{(2,170.3)}=3.225, p=0.042\right)$. Pollination type, its interaction with bloom phenology class, the random effect of year and its interactions with the fixed effects were not significant $(p>0.05)$. Early clones had significantly heavier berries than mid-season clones $(0.615 \pm 0.120$ (s.e.) g vs. $0.485 \pm 0.121 \mathrm{~g})$. Late clone berry weights $(0.530 \pm 0.119 \mathrm{~g})$ were not significantly different from early season or mid-season clone berry weights. There was a weak, but significant predictive relationship between fruit set and berry weights over all four years, with the variance in years accounted for by the random effect $\left(F_{(1,173)}=27.014, p<0.001\right.$, conditional $r^{2}=0.099$, Figure 3$)$.

When highly self-fertile clones ( $>60 \%$ fruit set when self-pollinated) were compared with less self-compatible clones we found that the interaction of self-fertility level (highly self-fertile vs. not) $\times$ pollination type (hand self-pollination vs. open pollination) determined fruit set, irrespective of bloom phenology time $\left(F_{(1,168)}=32.845, p<0.001\right)$. No other fixed or random effects were significant in explaining fruit set. Self-fertile clones had the highest fruit set when self-pollinated, both levels of self-fertility had intermediate fruit set under open pollination, and less self-fertile clones when self-pollinated had the lowest fruit set (Figure 4A). There was a trend toward highly self-fertile clones under open pollination having higher fruit set than less fertile open pollinated clones $(p=0.125)$. The interaction of self-fertility level $\times$ bloom phenology class was the only factor that determined berry weight $\left(F_{(2,163.2)}=4.206, p=0.046\right)$. Highly self-fertile clones that initiated flowering during early bloom and late bloom produced heavier berries than other clones (Figure 4B). 

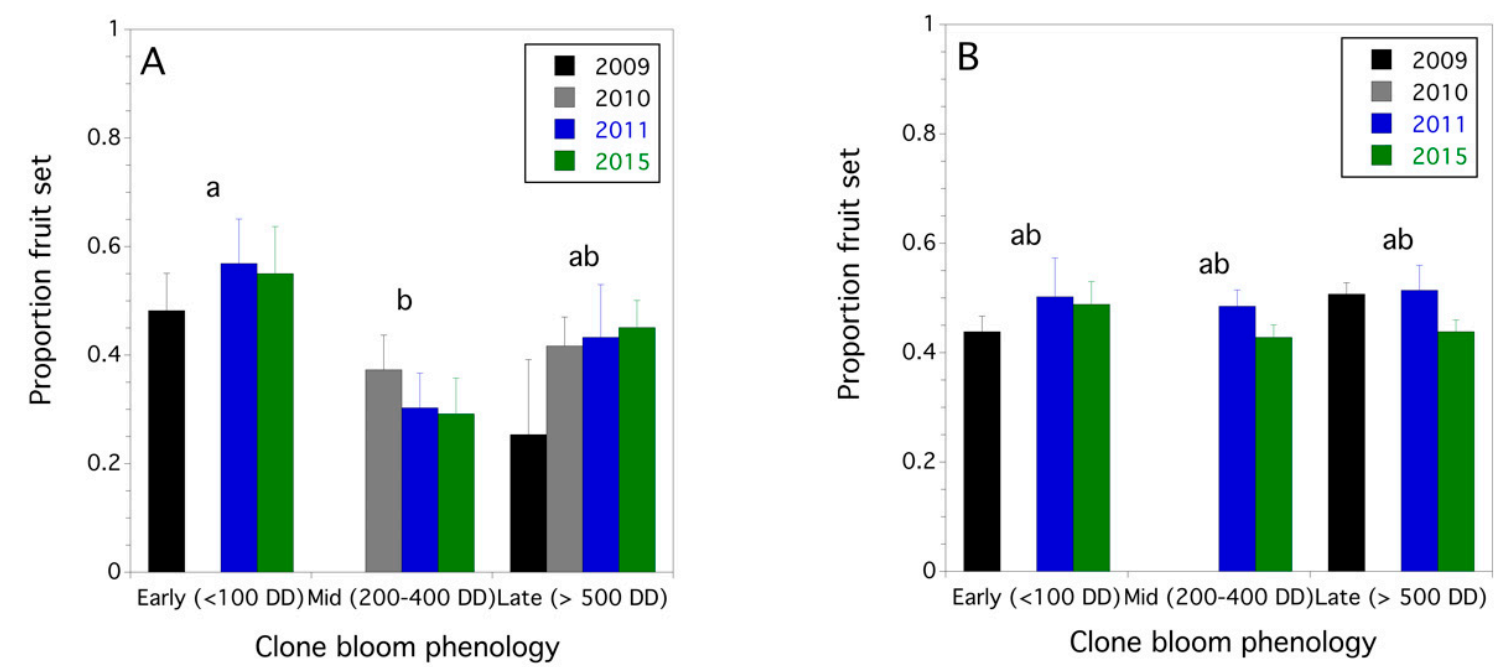

Figure 2. Overall proportion fruit set as a function of clones initiating bloom at different bloom phenological periods for hand self-pollination (A) and open pollination (B). Letters associated with bloom phenology classes that are the same are not significantly different (Tukey HSD, $\alpha=005$ ).

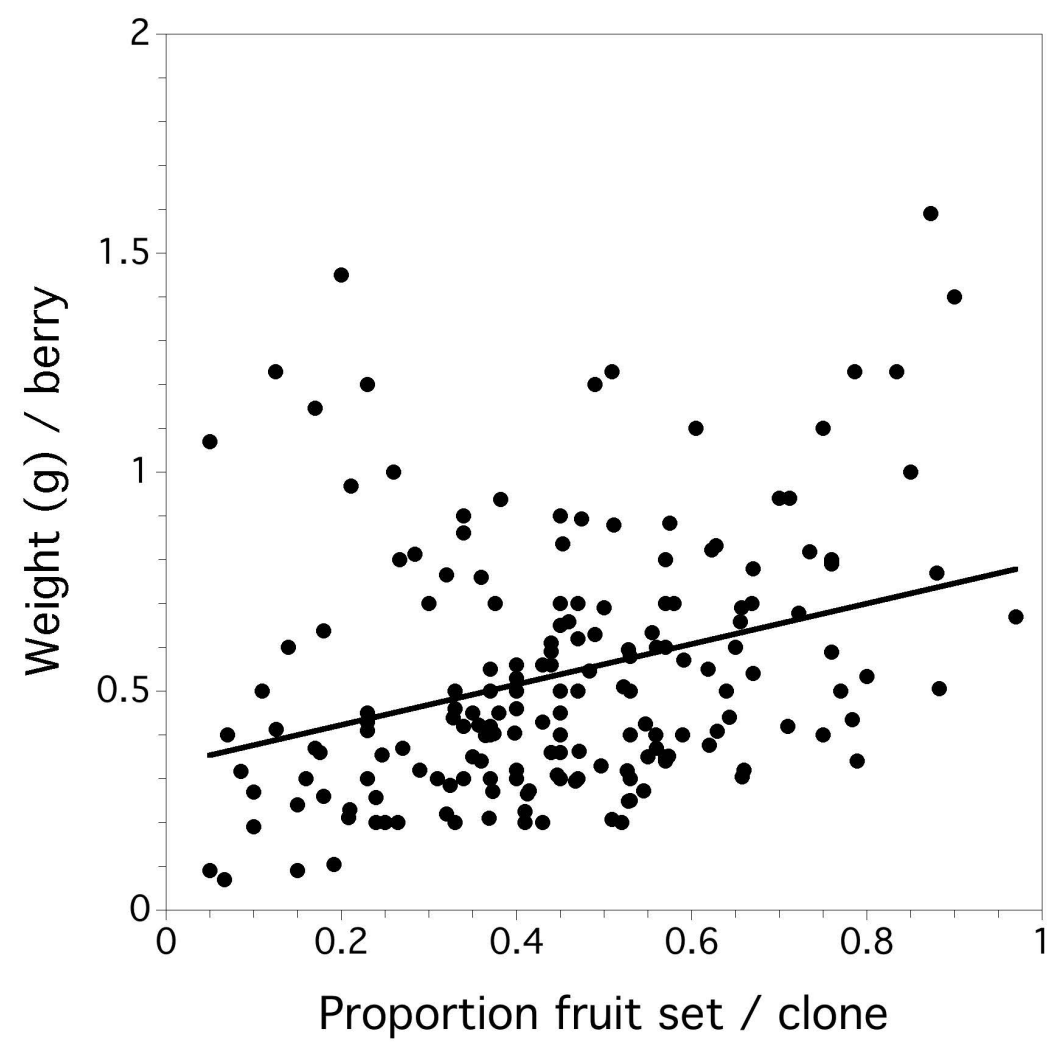

Figure 3. The linear relationship between proportion fruit set in a clone and resulting berry weight over all four years. 

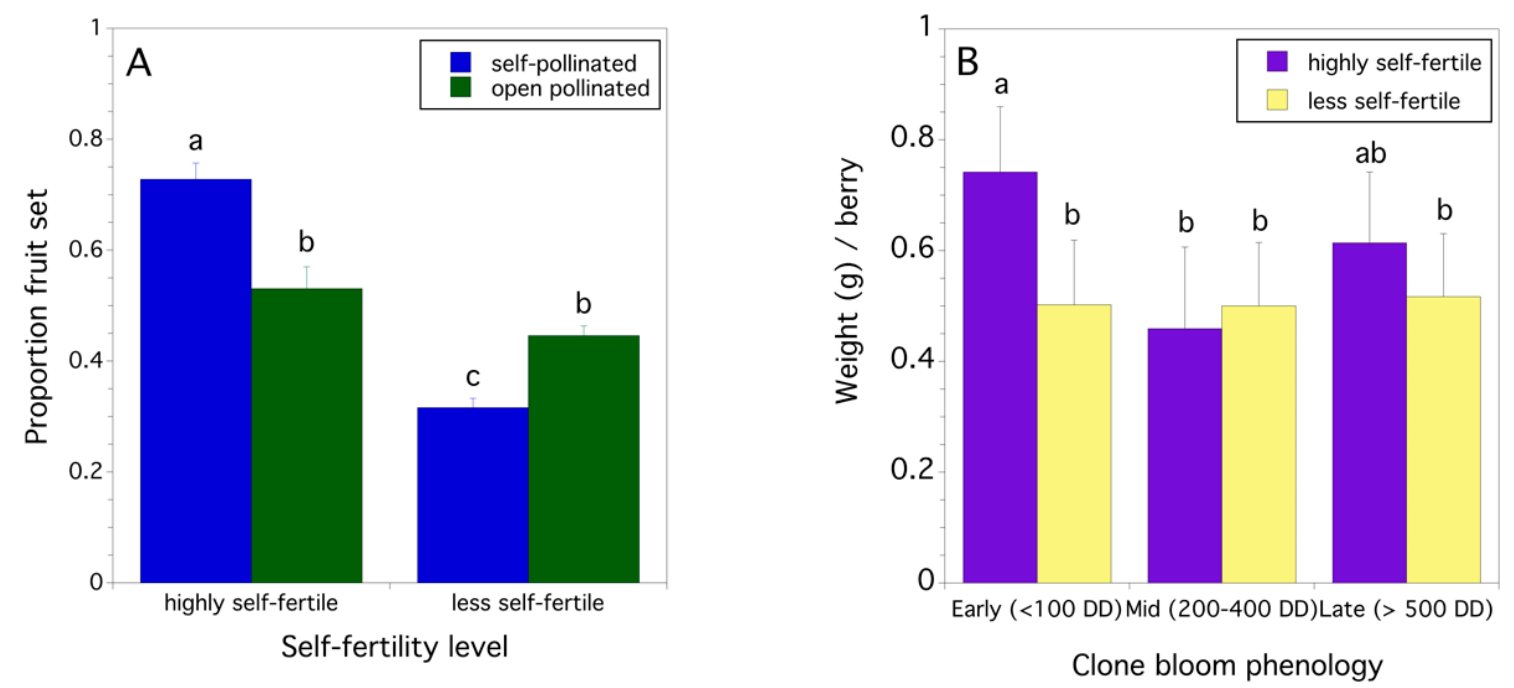

Figure 4. The effect of clones exhibiting high self-fertility interacting with pollination type (hand self-pollination vs. open pollination) on proportion fruit set (A) and the effect of high self-fertility interacting with bloom phenology class on berry weight (B). Letters associated with bloom phenology classes that are the same are not significantly different (Tukey HSD, $\alpha=005$ ).

\subsection{Bee Activity-Density Sampling}

Over all three years $(2009,2010, \& 2015)$ bumble bee queen activity-densities were found to be diluted over time as bloom progressed and the area of the field in bloom increased $\left(F_{(1,2)}=21.039\right.$, $p=0.044)$. There was no year (slope) effect (subject nested within year) $(p=0.212)$, and no year $\times$ bloom progression effect $(p=0.368)$. The progression of bloom and the rate of decline (dilution) of bumble bee queen activity-density over time is shown in Figure 5. Table 1 lists the parameter estimates for each sigmoidal model of bloom progression and bumble bee queen dilution by year. A repeated measures mixed model provided evidence that bloom progression had a negative effect on bumble bee activity-density over time $\left(F_{(1,18.2)}=92.559, p<0.001\right.$, conditional $r^{2}=0.853, \beta$ (slope for proportion bloom on bee activity-density) $=-0.004 \pm 0.0004$ ).
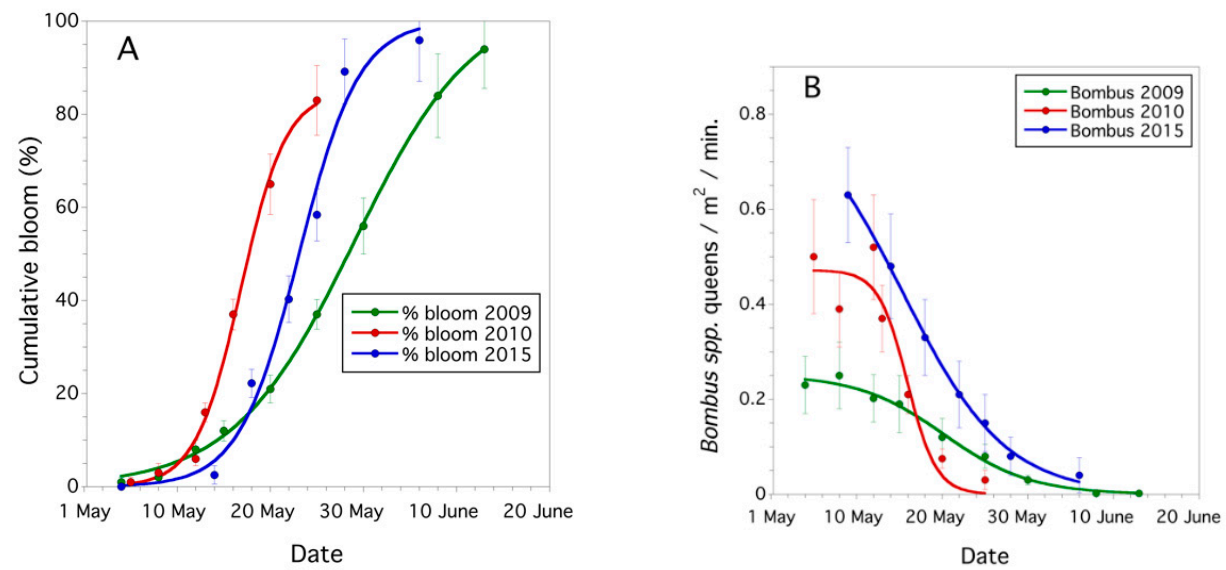

Figure 5. Wild blueberry field bloom progression and queen bumble bee activity-density over a three-year study $(2009,2010$, and 2015), percent cumulative bloom (A) and the dilution of queen foraging intensity as bloom progresses (B). Error bars are standard errors. Parameters for non-linear regression lines are listed in Table 1. 
Table 1. Model coefficients for sigmoidal model * describing bloom progression (\% bloom) and bumble bee queen dilution (bees $/ \mathrm{m}^{2} / \mathrm{min}$.) over the period of bloom.

\begin{tabular}{cccccc}
\hline Year & Model & Asymptote (a) & Shape (b) & Slope (c) & $\begin{array}{c}\text { Coefficient of Determination, } \\
\boldsymbol{p} \text { Value }{ }^{* * *}\end{array}$ \\
\hline \multirow{2}{*}{2009} & bloom & $88.508(7.517)^{* *}$ & $4.878(0.891)$ & $-0.234(0.049)$ & $r^{2}=0.947, \mathrm{X}^{2}{ }_{(8)}=4.31, p=0.83$ \\
& dilution & $0.252(0.013)$ & $-4.023(0.718)$ & $0.199(0.029)$ & $r^{2}=0.989, \mathrm{X}^{2}{ }_{(8)}=0.01, p>0.99$ \\
\hline \multirow{2}{*}{2010} & bloom & $85.128(3.541)$ & $6.921(0.637)$ & $-0.410(0.043)$ & $r^{2}=0.996, \mathrm{X}^{2}{ }_{(6)}=1.13, p=0.98$ \\
& dilution & $0.472(0.049)$ & $-9.435(4.994)$ & $0.592(0.308$ & $r^{2}=0.992, \mathrm{X}^{2}{ }_{(6)}=0.02, p>0.99$ \\
\hline \multirow{2}{*}{2015} & bloom & $100.151(6.468)$ & $7.187(1.217)$ & $-0.311(0.056)$ & $r^{2}=0.986, \mathrm{X}^{2}{ }_{(6)}=2.83, p=0.82$ \\
& dilution & $0.845(0.058)$ & $-2.597(0.335)$ & $0.168(0.012)$ & $r^{2}=0.998, \mathrm{X}^{2}{ }_{(6)}<0.01, p>0.99$ \\
\hline
\end{tabular}

${ }^{*}$ equation 1; ${ }^{* *}$ values in parentheses are standard errors. ${ }^{* * *}$ Coefficient of determination $\left(r^{2}\right)$ was approximated for non-linear model, $p$ value is based upon model goodness of fit to data (Chi-square test), comparison of observed sums of squares to that expected based upon a gaussian theoretical frequency distribution.

\section{Discussion}

Wild blueberry is characterized by herkogamy which reduces self-fertilization and potential inbreeding depression $[17,18,25]$. The reproduction of most wild blueberry clones (plants) is dependent upon outcrossing $[18,19,25]$. However, at a population level both self-pollination and pollination due to outcrossing probably occur simultaneously at different proportions. This is hypothesized in wild blueberry based upon the range of percent fruit set observed in clones that have been self-pollinated by hand (0-100\%) [18]. This type of "mixed mating system" or the occurrence of fertilization due to both self-pollination and outcrossing is not unusual in plants, especially invading species [52]. Our study shows that self-fertile clones tend to occur in higher proportion relative to less self-fertile clones during the onset of bloom in wild blueberry fields, but not in clones that initiate flowering in mid- and late bloom. We hypothesize that this bloom phenology biased pattern where a higher proportion of self-fertile clones initiate flowering early in the bloom season is a result of selection favoring an evolutionary life history strategy that has the advantage of attracting a high density of bees for pollination. We showed that bumble bee density, for all three years that we measured it in this study, was well timed with the start of bloom and that density was highest with the onset of bloom and as bloom progressed, the activity-density of bumble bee queens (bees $/ \mathrm{m}^{2} / \mathrm{min}$.) declined. This decline appears to be due to an increasing proportion of the land area in the field initiating bloom, and thus an increasing number of flowers available for bee visitation. In wild blueberry fields, observed average flower densities range from 9000-22,000 flowers $/ \mathrm{m}^{2}$ (Drummond unpublished data). This estimated flower density is the total over the entire bloom season and at any one point in time the density is less due to the average viability of flower stigmas being 7-10 d [9]. We think that increasing flower density throughout the bloom is the main cause of decreasing bee activity-density, although bumble bee queens may not be successful in establishing a colony and die [53]. In addition, queen bumble bee foraging ranges can be quite far $(5-6 \mathrm{~km})$ [54] and they can move to other more profitable foraging areas, although in maine wild blueberry growing regions, we doubt that there are many more profitable foraging areas compared to this mass flowering, pollen abundant resource.

Being able to attract bees at high densities because few con-specifics are flowering and being self-fertile maximizes the likelihood of pollination and subsequent fertilization. Self-pollination will most likely not result in maximum fitness and will probably contribute to inbreeding depression, a population characteristic that has been reported in wild blueberry $[17,18,25,39]$. Another disadvantage of such an evolutionary strategy was observed by us in 2010 when an early frost event killed a disproportionate number of flowers in early clones compared to later flowering clones.

Selection of self-fertile clones toward the end of bloom does not appear to be the case as shown in Figure 1. A similar outcrossing environment occurs toward the end of bloom, fewer neighboring clones. However, non-blueberry floral resources increase during bloom and this would intensify competition for bees among wild blueberry and other flowering plant species [55]. One might expect evolution of 
self-fertile clones under these late bloom season conditions where bees are attracted away from the few remaining wild blueberry clones in bloom to abundant non-blueberry flowering species. Lloyd [56] studying Leavenworthia crassa Rollins, suggested that when outcrossing was sub-optimal under certain conditions, such as limited numbers of pollinating insects, selection would be strong for self-fertility to evolve. moore and Lewis [57] studied the early blooming Clarkia xantiana A.Gray. They found that the earliest blooming individuals were self-fertile as is the case in wild blueberry. The self-fertile individuals had smaller flowers, shorter styles, and early maturing stigmas. They suggested that maintenance of self-fertile individuals in the population was due to frequent early droughts that killed the outcrossing individuals but not the faster developing early flowering self-fertile individual plants.

Many plant species have been hypothesized to have evolved self-fertilization or a mixed mating system from an obligate outcrossing mating system under conditions unfavorable to outcrossing [58] and several conditions have been put forth as prerequisites for the evolution of self-fertility such as: uncertainty of outcrossing, establishment of long-distance dispersal [59,60], earliness of flowering and lack of outcrossing conspecifics [44,57], expression of useful recessive genes [61], invading or colonizing plants at the edge or outside of their range where densities are low and aggregations are few [62], and where distinctive adapted populations are adjacent and crossing with extraneous pollen may lead to dilution of the adaptive characters [63]. Antovics [61] and Lloyd [44,64,65] provided evidence and models for self-fertility being an inherited trait, often linked to desirable morphological or growth and developmental traits and they concluded that this life history strategy would be evolutionary successful as long as outcrossing continued to occur along with self-fertilization minimizing ovule abortion and inbreeding depression. Early wild blueberry clones that are self-fertile are likely to overlap in bloom with later flowering obligate outcrossing clones because total flowering in a single clone may last 15-20 days over a $25-30$ d bloom period of the entire crop [9,19,20,32]. In addition, stigmas are viable for 7-10 d [9] which lengthens the time for pollination among highly self-fertile clones and their neighbors. Therefore, it is expected that self-fertile clones will also be sired by other clones in the field resulting in increased fitness, a reduction in inbreeding depression, and the maintenance of highly self-fertile early clones in the population $[44,61,65,66]$.

What is the significance of this phenomenon to wild blueberry growers? Figure 2A shows that overall fruit set was higher in early blooming clones than clones that initiated bloom in the middle of bloom, and late blooming clones were not significantly different in fruit set than either early or mid-blooming clones. This would not surprise many growers as it would be expected that early blooming clones might receive more bee visitation than mid-blooming clones due to the greater acreage of total bloom during peak bloom, but approximately the same number of bees, or at least a slight increase in bee density due to later emerging bee species, although not enough to track the increasing abundance of bloom. Overall berry weight (Figure 2B) was not different among bloom intervals. This again would not be surprising to growers if environmental conditions during any part of bloom did not adversely affect berry development and also because fruit set only explains a small proportion $(<0.10)$ of the variance in berry weight. However, the overall fruit set and berry weight data masks the contribution of self-fertile clones. This contribution (Figure 4A) can be seen to be significantly higher for fruit set over self-infertile clones when self-pollination occurs, but not during open pollination where outcrossing has been observed [31]. This suggests that self-fertile clones can reach high levels of fruit set when only self-pollen is available for pollination, but at the same time they are not at a disadvantage due to incompatibility with self-pollen or outcrossed pollen under conditions of open pollination. Bell et al. [18] referred to self-fertile clones as "universal mothers" as they attained high levels of fruit set with any sire's pollen. This was not the case with self-infertile clones. The resulting berry weight is higher in early bloom in self-fertile clones compared to self-infertile clones. The tendency for self-fertile clones to be higher yielding than self-infertile clones has been reported previously [18]. So, from a grower's perspective, self-fertile clones, while not constituting a large proportion of the population, appear to be dominant during the beginning of bloom, they attract a high density of bees resulting in high levels of fruit set and high berry weights, the combination of which 
suggests high potential yield. many growers do not have honey bees delivered to their fields until $25-30 \%$ bloom (FAD pers. obs.), therefore, much of the early bloom contributions to total yields are from native bees [7], a natural resource that is valued by growers [66-68]. A study by Schut et al. [69] in Nova Scotia corroborated our study on the importance of early blooming clones. They did not investigate the mechanism of fruit set due to self-fertile clones, but they found that plots with early blooming clones produced more than $70 \%$ of the yield in plots with clones that bloomed toward the end of the season. Their results suggest that pollination by bees in the beginning of bloom provides a large ecosystem service to wild blueberry production.

In conclusion, highly self-fertile clones initiate bloom across the entire bloom season, but their proportion relative to more self-sterile clones is highest in the beginning of bloom. These early self-fertile clones attract a high density of bumble bees (Apidae) and most likely other wild bees such as digger bees (Andrenidae), mason bees (Megachilidae) and sweat bees (Halictidae). As the bloom season progresses, later blooming clones experience a lower wild bee density due to a dilution effect of increasing floral density across the wild blueberry field. Highly self-fertile clones attain higher fruit set and berry weights, the combination of which is potential yield. Hopefully this information will be an incentive for growers to further conserve and protect wild bees on their farms.

Author Contributions: F.A.D. collected pollination in 2011 and 2015 and bee data in 2009, 2010, and 2015; conducted data entry and data analysis, interpreted the results, wrote the first draft of the manuscript. L.J.R. assisted in the conceptualization of the study, helped secure funding for the study, and edited the manuscript. All authors have read and agreed to the published version of the manuscript.

Funding: This research was partially funded by the maine Wild Blueberry Commission and The University of maine Agricultural Experiment Station, $\mathrm{mE0}$-21505. In addition, a cooperative agreement from the U.S. Department of Agriculture helped fund this research. This is maine Agricultural Experiment Station Publication number 3755 .

Acknowledgments: We would like to thank the wild blueberry growers who allowed us to use their fields for this research. We would like to thank our colleague, Daniel J. Bell for initiating this study with us. It was his question of whether "selfers" were plants worth identifying, protecting and promoting in wild blueberry fields that initiated this study. He collected the first two years of data in this study. We would also like to thank the University of maine Research Farm technicians, Chris mcManus and Joshua Stubbs, who helped us collect data for this study. We also thank two anonymous reviewers for their critical and thorough reviews. Their suggestions improved our manuscript.

Conflicts of Interest: The authors declare no conflicts of interest.

\section{References}

1. Rowland, L.J.; Drummond, F.A.; graham, J.; Alkharouf, N.; Buck, E.J.; Hancock, J.F.; Bassil, N.V.; Finn, C.E.; Olmstead, J.W. generating genomic tools for blueberry improvement. Int. J. Fruit Sci. 2012, 12, 276-287. [CrossRef]

2. Jones, M.S.; Vanhanen, H.; Peltola, R.; Drummond, F. A global review of arthropod-mediated ecosystem-services in Vaccinium berry agroecosystems. Terr. Arthropod Rev. 2014, 7, 41-78. [CrossRef]

3. Yarborough, D.E. Wild Blueberry Culture in maine. Wild Blueberry Fact Sheet. No. 220, Bulletin No. 2088. 2009. Available online: https://extension.umaine.edu/blueberries/factsheets/production/wildblueberryculture-in-maine/ (accessed on 6 may 2020).

4. Vander Kloet, S.P. The genus Vaccinium in North America; Agriculture Canada: Ottawa, ON, Canada, 1988.

5. Drummond, F.A.; Smagula, J.; Annis, S.; Yarborough, D. Organic wild blueberry production. Tech. Bull. maine Agric. For. Exp. 2009, 852, 43. Available online: https://digitalcommons.library.umaine.edu/aes_bulletin/2/ (accessed on 6 August 2020).

6. Strik, B.C.; Yarborough, D.E. Blueberry production trends in North America, 1992 to 2003, and predictions for growth. HortTechnology 2005, 15, 391-398. [CrossRef]

7. Asare, E.; Hoshide, A.K.; Drummond, F.A.; Chen, X.; Criner, G.K. Economic risk of bee pollination in maine wild blueberry, Vaccinium angustifolium Aiton. J. Econ. Entomol. 2017, 110, 1980-1992. [CrossRef]

8. Yarborough, D.; Drummond, F.A.; Annis, S.; D'Appollonio, J. maine Wild blueberry systems analysis. Acta Hort. 2017, 1180, 151-160. [CrossRef] 
9. Drummond, F.A. Reproductive biology of wild blueberry (Vaccinium angustifolium Aiton). Agric. 2019, 9, 69. [CrossRef]

10. Eaton, L.J.; murray, J.E. Relationships of pollinator numbers in blueberry fields to fruit development and yields. In VI International Symposium on Vaccinium Culture; Acta Hort: Leuven, Belgium, 1996; pp. 181-188.

11. Cutler, G.C.; Reeh, K.W.; Sproule, J.M.; Ramanaidu, K. Berry unexpected: Nocturnal pollination of lowbush blueberry. Can. J. Plant Sci. 2012, 92, 707-711. [CrossRef]

12. Dicenta, F.; Ortega, E.; Canovas, J.A.; Egea, J. Self-pollination vs. cross-pollination in almond: Pollen tube growth, fruit set and fruit characteristics. Plant Breed. 2002, 121, 163-167. [CrossRef]

13. Scorza, R.; Bassi, D.; Liverani, A. genetic interactions of pillar (columnar), compact, and dwarf peach tree genotypes. J. Hort. Sci. 2002, 127, 254-261. [CrossRef]

14. Frankel, R.; galun, E. Pollination mechanisms, Reproduction and Plant Breeding (Vol. 2), 1st ed.; Springer: Berlin, germany, 2012; p. 281.

15. Ramírez, F.; Davenport, T.L. Apple pollination: A review. Sci. Hort. 2013, 162, 188-203. [CrossRef]

16. Hepler, P.R.; Yarborough, D.E. Natural variability in yield of lowbush blueberries. J. Hort. Sci. 1991, 26, 245-246. [CrossRef]

17. Bell, D.J.; Rowland, L.J.; Smagula, J.; Drummond, F.A. Recent advances in the biology and genetics of lowbush blueberry. Maine Agric. Exp. Stn. Tech. Bull. 2009, 203, 36.

18. Bell, D.J.; Rowland, L.J.; Stommel, J.; Drummond, F.A. Yield variation among clones of lowbush blueberry as a function of kinship and self-compatibility. J. Hort. Sci. 2010, 135, 1-12.

19. Qu, H.; Drummond, F.A. Simulation-based modeling of wild blueberry pollination. Electron. Comput. Agric. 2018, 144, 94-101. [CrossRef]

20. Bajcz, A.; Hiebeler, D.; Drummond, F.A. grid-Set-Match, an agent-based simulation model, predicts fruit set for the maine lowbush blueberry (Vaccinium angustifolium) agroecosystem. Ecol. model. 2017, 361, 80-94. [CrossRef]

21. Bajcz, A.W.; Drummond, F.A. Flower power: Floral and resource manipulations reveal the consequences of reproductive effort in lowbush blueberry (Vaccinium angustifolium). Ecol. Evol. 2017, 7, 5645-5659. [CrossRef] [PubMed]

22. Bajcz, A.W.; Drummond, F.A. Bearing fruit: Flower removal reveals the trade-offs associated with high reproductive effort for lowbush blueberry. Oecologia 2017, 185, 13-26. [CrossRef]

23. Aalders, L.E.; Hall, I.V. Pollen incompatibility and fruit set in lowbush blueberries. Can. J. gent. Cytol. 1961, 3, 300-307. [CrossRef]

24. Wood, G.W. Self-fertility in the lowbush blueberry. Can. J. Plant Sci. 1968, 48, 431-433. [CrossRef]

25. Hokanson, K.; Hancock, J. Early-acting inbreeding depression in three species of Vaccinium (Ericaceae). Sex. Plant Reprod. 2000, 13, 145-150. [CrossRef]

26. Bell, D.J.; Rowland, L.J.; Zhang, D.; Drummond, F.A. Spatial genetic structure of lowbush blueberry, Vaccinium angustifolium, in four fields in maine. Botany 2009, 87, 932-946. [CrossRef]

27. Bell, D.J.; Rowland, L.J.; Drummond, F.A. Fine-scale spatial genetic structure associated with Vaccinium angustifolium Aiton (Ericaceae). Int. J. Bot. 2012, 2, 72-82.

28. Myra, M.; macKenzie, K.; Vander Kloet, S.P. Investigation of a possible sexual function specialization in the lowbush blueberry (Vaccinium angustifolium Aition. Ericaceae). Small Fruits Rev. 2004, 3, 313-324. [CrossRef]

29. Bell, D.J.; Drummond, F.A.; Rowland, L.J. Evidence of functional gender polymorphisms in a population of the hermaphroditic lowbush blueberry (Vaccinium angustifolium Ait.). Botany 2012, 90, 393-399. [CrossRef]

30. Bell, D.J.; Rowland, L.J.; Drummond, F.A. Does pollen neighborhood affect berry yield in lowbush blueberry (Vaccinium angustifolium Ait.). Int. J. Fruit Sci. 2012, 12, 65-74. [CrossRef]

31. Rowland, L.J.; Ogden, E.L.; Bell, D.J.; Drummond, F.A. Pollen-mediated gene flow in managed fields of lowbush blueberry. Can. J. Plant Sci. 2019, 100, 95-102. [CrossRef]

32. White, S.N.; Boyd, N.S.; van Acker, R.C. growing degree-day models for predicting lowbush blueberry (Vaccinium angustifolium Ait.) ramet emergence, tip dieback, and flowering in Nova Scotia, Canada. HortScience 2012, 47, 1014-1021. [CrossRef]

33. Drummond, F.A.; Dibble, A.C.; Stubbs, C.; Bushmann, S.; Ascher, J.; Ryan, J. A natural history of change in native bees associated with lowbush blueberry in maine. Northeast. Northeast. Nat. 2017, 24, 49-68. [CrossRef] 
34. Collins, J.A.; Drummond, F.A. Fertilizer and fungicides: Effects on wild blueberry growth, insect attack, and leaf spot disease incidence. In Proceedings of the North American Blueberry Research and Extension Workers Conference, Orono, mE, USA, 12-15 August 2018; p. 24.

35. Camp, W.H. The North American blueberries with notes on other groups of Vacciniaceae. Brittonia 1945, 25, 203-275. [CrossRef]

36. Vander Kloet, S.P. The taxonomic status of Vaccinium boreale. Can. J. Bot. 1997, 55, 281-288. [CrossRef]

37. Vander Kloet, S.P. Systematics, distribution, and nomenclature of the polymorphic Vaccinium angustifolium. Rhodora 1978, 80, 358-376.

38. Ramsey, J.; Schemske, D.W. Pathways, mechanisms, and rates of polyploid formation in flowering plants. Ann. Rev. Ecol. Syst. 1998, 29, 467-501. [CrossRef]

39. Hokanson, K.; Hancock, J. Levels of allozymic diversity in diploid and tetraploid Vaccinium sect. Cyanococcus (blueberries). Can. J. Plant Sci. 1998, 78, 327-332. [CrossRef]

40. Morgan, M.T.; Wilson, W.G.; Knight, T.M. Plant population dynamics, pollinator for aging, and the selection of self-fertilization. Am. Nat. 2005, 166, 169-183. [CrossRef]

41. Lloyd, D.G.; Schoen, D.G. Self- and cross-fertilization in plants. I. Functional dimensions. Int. J. Plant Sci. 1992, 153, 358-369. [CrossRef]

42. Eckert, C.G.; Schaefer, A. Does self-pollination provide reproductive insurance in Aquilegia canadensis (Ranunculaceae). Am. J. Bot. 1998, 85, 919-924. [CrossRef]

43. Schueller, S.K. Self-pollination in island and mainland populations of the introduced hummingbird-pollinated plant, Nicotiana glauca (Solanaceae). Am. J. Bot. 2004, 91, 672-681. [CrossRef]

44. Lloyd, D.G. Some reproductive factors affecting the selection of self-fertilization in plants. Am. Nat. 1979, 113, 67-79. [CrossRef]

45. Bell, D.J. Spatial and genetic factors influencing yield in lowbush blueberry (Vaccinium angustifolium Ait.) in maine. Ph.D. Thesis, University of maine, Orono, mE, USA, 2009.

46. Drummond, F.A. Wild blueberry fruit drop: A Consequence of Seed Set. Agronomy 2020, 10, 939. [CrossRef]

47. SAS Institute. JMP®Version 14; SAS Institute Inc.: Cary, NC, USA, 2017.

48. Kuznetsova, A.; Brockhoff, P.V.; Christensen, R.H.B. Lmertest Package: Tests in linear mixed effects models. J. Stat. Softw. 2017, 88, 1-26. [CrossRef]

49. Drummond, F.A. Behavior of bees associated with the wild blueberry agro-ecosystem in the USA. Int. J. Entomol. Nematol. 2016, 2, 27-41.

50. Cutler, G.C.; Nams, V.O.; Craig, P.; Sproule, J.M.; Sheffield, C.S. Wild bee pollinator communities of lowbush blueberry fields: Spatial and temporal trends. Basic Appl. Ecol. 2014, 16, 73-85. [CrossRef]

51. Karem, J.; Drummond, F.A.; Woods, S.A.; Stubbs, C. The relationships between Apocrita wasp populations and flowering plants in maine's wild lowbush blueberry agroecosystems. J. Biocontrol Sci. Technol. 2010, 20, 257-274. [CrossRef]

52. Goodwillie, C.; Kalisz, S.; Eckert, C.G. The evolutionary enigma of mixed mating systems in plants: Occurrence, theoretical explanations, and empirical evidence. Annu. Rev. Ecol. Evol. Syst. 2005, 36, 47-49. [CrossRef]

53. Carvell, C.; Bourke, A.F.; Dreier, S.; Freeman, S.N.; Hulmes, S.; Jordan, W.C.; Redhead, J.W.; Sumner, S.; Wang, J.; Heard, M.S. Bumblebee family lineage survival is enhanced in high-quality landscapes. Nature 2017, 543, 547-549. [CrossRef]

54. Greenleaf, S.; Williams, N.; Winfree, R.; Kremen, C. Bee foraging ranges and their relationship to body size. Oecologia 2007, 153, 589-596. [CrossRef]

55. Drummond, F.A.; Ballman, E.; Collins, J. Are they weeds or a life force? Or sustainability on the edge. Spire maine J. Conserv. Sustain. 2017. Available online: https://umaine.edu/spire/2017/05/04/drummond-et-al/ (accessed on 12 July 2020).

56. Lloyd, D.G. Evolution of self-compatibility and racial differentiation in Leavenworthia (Cruciferae). Contrib. gray Herb. Harv. Univ. 1965, 195, 1-134.

57. Moore, D.M.; Lewis, H. The evolution of self-pollination in Clarkia xantiana. Evolution 1965, 19, $104-114$. [CrossRef]

58. Antonovics, J. Evolution in closely adjacent plant populations V. Evolution of self-fertility. Heredity 1968, 23, 219-238. [CrossRef]

59. Baker, H.G. Self-compatibility and establishment after "long-distance" dispersal. Evolution 1955, 9, 347-348. 
60. Holsinger, K.E. Dispersal and plant mating systems: The evolution of self-fertilization in subdivided populations. Evolution 1986, 40, 405-413. [CrossRef] [PubMed]

61. Antonovics, J. Evolution in closely adjacent plant populations X: Long-term persistence of prereproductive isolation at a mine boundary. Heredity 2006, 97, 33-37. [CrossRef] [PubMed]

62. Daehler, C.C. Variation in self-fertility and the reproductive advantage of self-fertility for an invading plant (Spartina alterniflora). Evol. Ecol. 1998, 12, 553-568. [CrossRef]

63. McNeilly, T. Evolution in closely adjacent plant populations III. Agrostis tenuis on a small copper mine. Heredity 1968, 23, 99-108.

64. Lloyd, D.G. Demographic factors and mating patterns in angiosperms. In Demography and Evolution in Plant Populations; Solbrig, O.T., Ed.; Blackwell: Oxford, UK, 1980; pp. 67-88.

65. Lloyd, D.G. Benefits and handicaps of sexual reproduction. Evol. Biol. 1980, 13, 69-111.

66. Hanes, S.P.; Collum, K.; Hoshide, A.K.; Drummond, F.A.; Asare, E. Farmer perceptions of native pollinators and pollination strategies in the lowbush blueberry industry. Renew. Agric. Food Syst. 2013, 28, 1-8.

67. Rose, A.; Drummond, F.A.; Yarborough, D.E.; Asare, E. maine Wild Blueberry Farmers: A 2010 Economic and Sociological analysis of a Traditional Downeast Crop in Transition. Maine Agric. Exp. Stn. misc. Bull. 2013, 445, 24. Available online: https://digitalcommons.library.umaine.edu/cgi/viewcontent.cgi? article=1017\& context=aes_miscreports (accessed on 6 August 2020).

68. Hoshide, A.K.; Drummond, F.A.; Stevens, T.H.; Venturini, E.M.; Hanes, S.P.; Sylvia, M.M.; Loftin, C.S.; Yarborough, D.E.; Averill, A.L. What is the value of wild bee pollination for wild blueberries and cranberries and who values it. Environments 2018, 5, 98. [CrossRef]

69. Schut, L.; Tyedmers, P.; Cutler, G.C.; melathopoulos, A. Is early pollination to lowbush blueberry an ecosystem service or disservice. Agric. Ecosyst. Environ. 2017, 239, 368-375. [CrossRef]

(C) 2020 by the authors. Licensee MDPI, Basel, Switzerland. This article is an open access article distributed under the terms and conditions of the Creative Commons Attribution (CC BY) license (http://creativecommons.org/licenses/by/4.0/). 